\title{
$\mathrm{PBL}$ 수행절차와 ILS 개발절차의 수명주기별 프로세스 모델링 및 상호 연계성의 개선에 관한 연구 \\ 주현준 ${ }^{1}$, 이재천 $2^{*}$ \\ ${ }^{1}$ 국방과학연구소 항공체계단, ${ }^{2}$ 아주대학교 시스템공학과
}

\section{On Modeling the PBL Process and the ILS Development from a Life Cycle View with Resultant Enhanced Interrelationship}

\author{
Hyun-Jun $\mathrm{Ju}^{1}$ and Jae-Chon $\mathrm{Lee}^{2^{*}}$ \\ ${ }^{1}$ Aircraft Systems PMO, ADD \\ ${ }^{2}$ Dept. of Systems Engineering, Ajou University
}

\begin{abstract}
요 약 현재의 국내 군수 환경은 운용단계에 있는 무기체계에 대해 PBL 개념의 적용이 확대되고 있는 추세이다. 본 연구에서는 전수명주기에 걸쳐 PBL 적용 프로세스와 ILS 요소 개발을 모델링 해 봄으로써 PBL 적용 프로세스의 개선안을 도출하려고 한다. 특히 개발초기 단계부터 $\mathrm{PBL}$ 적용 프로세스를 모델링 해 봄으로써 개선을 도모하였다. 또한, ILS 개발 시점부터 PBL 개념이 반영되도록 ILS 요소 개발과의 상관관계를 설정함으로써 운용단계에 있는 체 계가 아닌 개발단계부터 ILS 개발절차에 PBL을 고려하는 개선방안을 제공한다. 기존에 국내에서 적용 중인 PBL 개 념이 ILS의 보급체계와의 연계성에만 국한된 개념이라면 이를 확장해서 개발체계 전체의 가용도, 신뢰도, 군수지원 비용 등을 고려한 개선된 $\mathrm{PBL}$ 적용이 가능하다.
\end{abstract}

\begin{abstract}
The demand on applying the performance-based logistics (PBL) in the operational phase of the weapon systems development is increasing these days. Therefore, the enhancement of the PBL concept and process needs to be done. This is the objective of the paper. As a method of approach, a modeling method is adopted to cover the whole life cycle of the weapon systems development from the concept development to the operation. The modeling results for the PBL process yield an useful suggestion for improvement. Also, by analyzing the interrelationship model between the PBL process and the integrated logistics support (ILS) procedure, it is possible to take advantage of the PBL concept in the ILS elements development, which is usually carried out from the beginning of the development phase, a lot earlier than the operational phase. Note that the PBL concept has been restrictively applied in only the supply support among many ILS elements up until now. However, the results obtained in the paper can make it also possible to consider the availability, reliability, logistics support, cost and so on from the early phase of the weapon systems development.
\end{abstract}

Key Words : PBL Process, ILS Interrelationship, MIL-STD-1388-1A

\section{1. 서론}

PBL(Performance Based Logistics; 성과기반 군수지원) 은 시스템 신뢰도를 증가시키며 순기비용을 줄일 수 있 는 기술 및 프로세스에 대한 공급자의 투자를 유도하는
보상체계를 활용한다. 기존 지원 계약은 보상이 없는 공 급자의 판매에 따른 수익에만 초점이 맞추어져 있는 반 면에 PBL은 체계의 가용도와 같은 고객으로부터 제시된 성능을 나타내는 성과지표에 초점이 있다. 아울러, 명확 한 권리와 책임이 명시된 장기 지원 계약을 통하여 체계

*Corresponding Author: Jae-Chon Lee

Tel: +82-31-219-3941, email: jaelee@ajou.ac.kr

접수일 12년 09월 03일 수정일 12년 10월 04일

게재확정일 12 년 10 월 11 일 

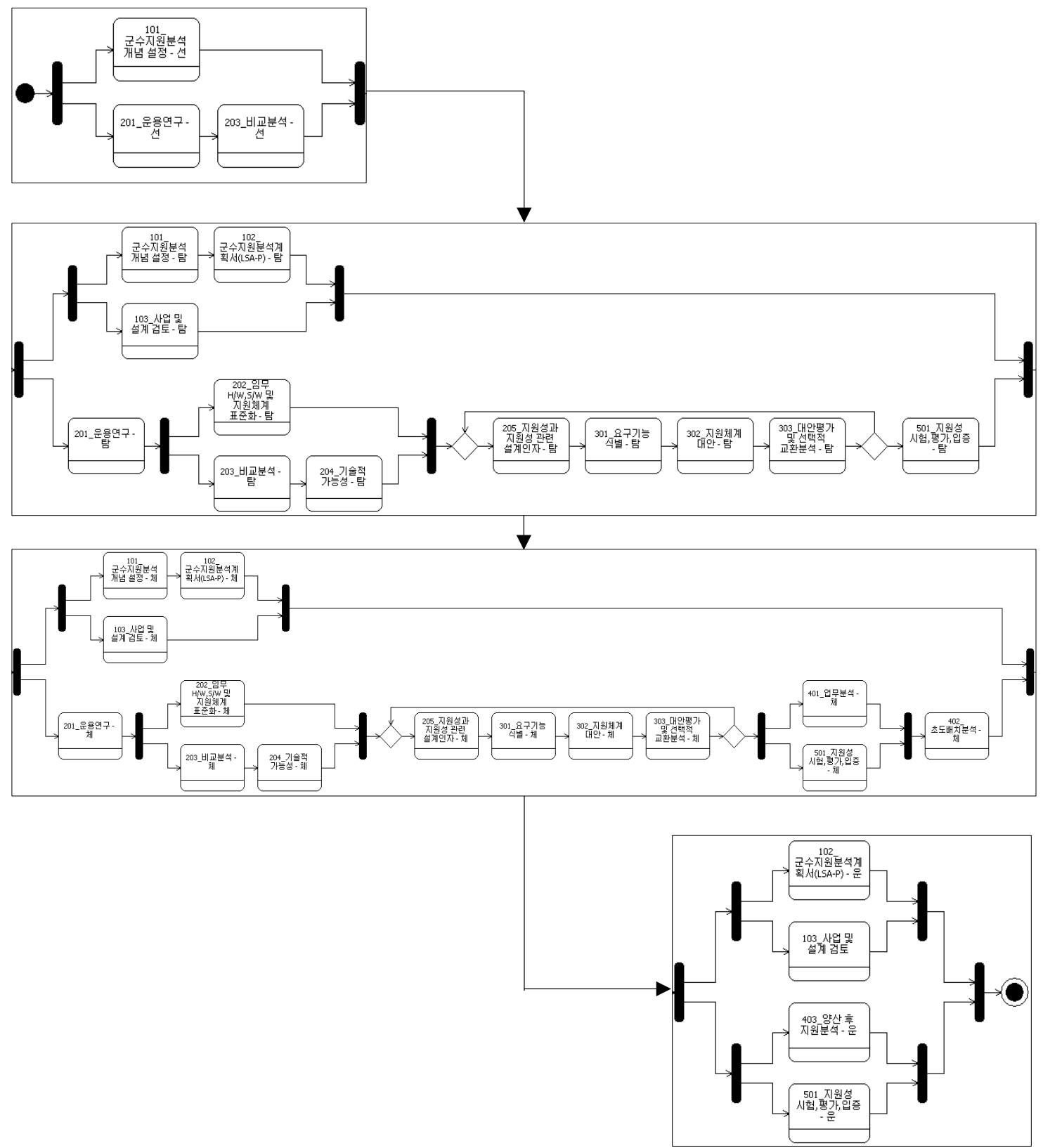

[그림 1] ILS 개발 프로세스(MIL-STD-1388-1A)

[Fig. 1] ILS Development Process(MIL-STD-1388-1A)

준비태세를 최적화하고 무기체계의 성능을 만족하기 위 하여 설계된 종합적이면서 가용한 성과지표로서 지원을 구매하는 것이다[1,2].

종합군수지원(ILS; Integrated Logistics Support)은 체 계의 효과적이고 경제적인 군수지원을 보장하기 위하여 소요 제기 시부터 설계, 개발, 획득 및 폐기 시까지의 제
반 군수지원 요소를 종합 관리하는 활동이다. 종합군수지 원은 11 대 요소에 대한 개발을 수행한 후 사용자에게 제 공하여 향후 운용 시 필요한 제반 요소를 제공하며 운용 단계에서는 사용자가 운영의 책임이 있다. 반면, $\mathrm{PBL}$ 은 사용자가 원하는 성과지표가 달성될 수 있도록 개발자가 운용단계에서도 관여하여 계속적인 후속지원을 수행하는 


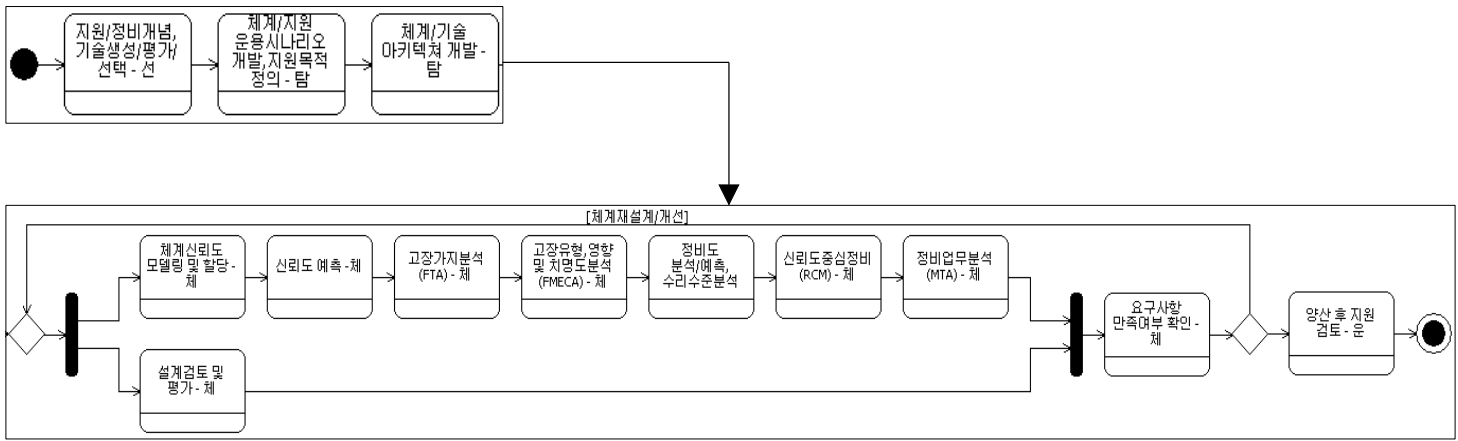

[그림 2] ILS 개발 프로세스(DoD)

[Fig. 2] ILS Development Process(DoD)

체제를 갖고 있다.

국내에서도 PBL 개념의 도입 필요성이 인식되고 일부 체계에 적용하는 단계에 있지만 수리부속과 같은 보급지 원의 단일 요소만이 고려되고 있는 현실이다. 즉, $\mathrm{PBL}$ 의 성과지표로서는 가용도, 신뢰도, 준비태세, 군수지원비용 등 여러 가지 요소 중에서 현재는 수리부속의 인도응답 기간과 같은 보급측면이 성과지표로 적용되고 있다[3]. 또한, 수명주기별 세부적인 수행절차가 규정상에 구체적 으로 명시되어 있지 않으며 일부 연구에서는 기관별 업 무분장 내용과 성과기반 계약을 중심으로 절차를 제시하 고 있다[4].

외국에서는 이러한 PBL 개념과 업무절차 및 적용효과 에 대해서 많은 수행결과들이 제시되고 있다. 그러나 무 기체계의 수명주기에 따른 PBL 업무절차가 제시되는 자 료마다 약간의 차이점이 있으며, 선택적으로 적용되고 있 는 현실이다.

따라서, 본 연구에서는 이러한 자료를 바탕으로 국내 에 적용 가능한 수명주기단계별 PBL 프로세스 안을 프로 세스 모델링 기법을 사용하여 제시한다. 프로세스 모델링 은 시스템공학(SE) 분석 지원 도구인 Vitech사의 Core $8^{\circledR}$ 프로그램을 이용하여 수행하였다. 또한, 개발되는 체계에 있어서 PBL 개념이 ILS 개발 이후에 고려되는 것이 아니 라 ILS 개발 시점부터 이를 반영한 ILS 요소 개발이 이루 어져야 하는 상관관계를 제시함으로써 ILS 개발절차에 $\mathrm{PBL}$ 을 고려한 개선방안을 제시한다.

\section{2. 기존 ILS 분석 절차}

ILS 개발과 관련된 분석 절차는 MIL-STD-1388-1A 표 준서와 $\mathrm{DoD}$ (Department of Defense) 지침서에 명시되어 있다[5,6].

\subsection{MIL-STD-1388-1A 표준서상의 ILS 분석 절차}

기존 ILS 개발 분석업무는 MIL-STD-1388-1A를 기준 으로 수행하였다. 본 기준은 업무 100 에서 500 까지의 업 무로 세분화되어 구성되어 있으며 업무 100 은 사업관리 측면의 활동들이 기술되어 있다. 수명주기단계별 분석업 무를 모델링으로 표시하면 그림 1과 같다[5]. 단, 수명주기 단계상 선은 선행연구, 탐은 탐색개발, 체는 체계개발, 운 은 양산/운용 단계를 의미하며 이하 동일하다. 적용하는 업무가 각 수명주기단계별로 상이함을 식별할 수 있다. 체 계개발단계에서의 수행업무는 탐색개발단계와 비교하였 을 때 설계가 구체화됨에 따라 세부업무분석과 운용을 위 한 초도배치 분석업무가 추가적으로 필요하게 된다.

\subsection{DoD 지침서상의 ILS 분석 절차}

$\mathrm{DoD}$ 지침서에서 제시하는 수명주기단계별 ILS 분석 업무절차는 MIL-STD-1388-1A 표준서와 비교 시 약간의 차이가 있으며 이를 표시하면 그림 2와 같다[6]. $\mathrm{DoD}$ 지 침서상의 절차는 지원성 측면 외에 신뢰도 및 정비도 업 무를 추가로 고려하였다는 점에서 MIL-STD-1388-1A 표 준서상의 절차와 차별성이 있다. 이는 추후 $\mathrm{PBL}$ 성과지 표의 하나인 신뢰도와의 연계성을 설정할 수 있다.

\section{3. $\mathrm{PBL}$ 업무 절차 및 효용성}

PBL 업무수행절차는 NAVSEA(Naval Sea Systems Command)와 DAU(Defense Acquisition University)의 지 침서에서 정의하고 있다[2,7].

NAVSEA 지침서에서는 PBL에 대한 분석, 초도획득, 
최종 획득 단계로 구분하여 그림 3 과 같이 정의한다.

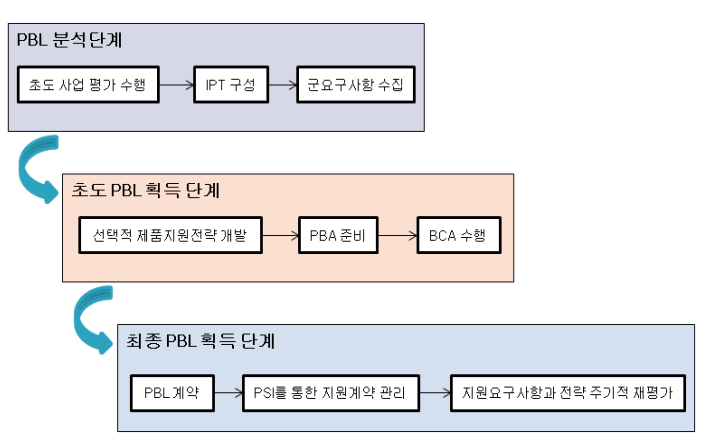

[그림 3] PBL 업무 절차(NAVSEA)

[Fig. 3] PBL Task Procedure(NAVSEA)

$\mathrm{DAU}$ 지침서에서는 설정, 계획, 실행 및 조정단계로 구분하여 그림 4 와 같이 정의하고 있다.

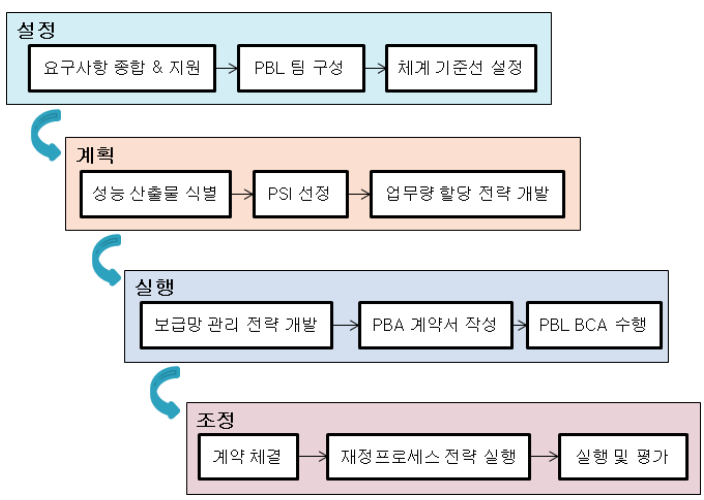

[그림 4] PBL 업무 절차(DAU)

[Fig. 4] PBL Task Procedure(DAU)

상기 내용을 비교하면 그림 3 의 초도 $\mathrm{PBL}$ 획득 및 최종 $\mathrm{PBL}$ 획득업무는 그림 4의 실행 및 조정업무와 각각 유사 하며, 그림 3의 PBL 분석업무는 그림 4에서 설정 및 계 획업무로 더욱 세분화되어 표현되어 있다.

$\mathrm{PBL}$ 개념의 체계에 대한 적용 효과는 일부 운용체계 의 몇 가지 성과지표에 대하여 가시적인 성과를 나타내 고 있다[8,9].

표 1 은 가용도 지표에 대한 개선 효과를 표현하고 있다.

표 2는 보급지원의 성과지표에 해당하는 고객대기시 간(CWT : Customer Wait Time)에 대한 효과를 보여준다. 고객대기시간은 수리부속품에 대한 청구부터 수령까지 걸리는 시간으로 정의한다.
[표 1] PBL 적용에 따른 가용도 개선효과

[Table 1] Availability Improvement by Applying PBL Concept

\begin{tabular}{|c|c|c|}
\hline 대상 시스템 & PBL 적용 전 & PBL 적용 후 \\
\hline F/A-18 SMS & $65 \%$ & $98 \%$ \\
\hline APU & $70 \%$ & $90 \%$ \\
\hline CIWS & $85 \%$ & $95 \%$ \\
\hline Tires & $81 \%$ & $98 \%$ \\
\hline AEGIS & $85 \%$ & $95 \%$ \\
\hline H-60 Avionics & $71 \%$ & $85 \%$ \\
\hline
\end{tabular}

[표 2] $\mathrm{PBL}$ 적용에 따른 $\mathrm{CWT}$ 개선효과

[Table 2] CWT Improvement by Applying PBL Concept

\begin{tabular}{|c|c|c|}
\hline 대상 시스템 & PBL 적용전 & PBL 적용후 \\
\hline F-18 SMS & 47 일 & 7일 \\
\hline APU & 162 일 & 38 일 \\
\hline
\end{tabular}

\section{4. 수명주기별 $\mathrm{PBL}$ 프로세스 모델링}

각 수명주기단계별 $\mathrm{PBL}$ 세부 수행업무에 대하여 AFLMA(Air Force Logistics Management Agency), DoD 에서 각각 제시하고 있다[10,11]. 이를 바탕으로 수명주 기단계별로 세부 수행 업무들 간의 상호 연계성을 고려 하여 모델링으로 표현하고 이를 분석하여 국내 현실에 적합한 프로세스 개선안을 제시한 결과는 다음과 같다.

\subsection{AFLMA 기준서상의 $\mathrm{PBL}$ 모델링}

AFLMA 기준서에서는 개발단계별로 PBL 관련 수행 업무를 정의하고 있다[10]. 이러한 수행 업무들 간의 상호 연관성을 고려하여 모델링으로 표현하면 그림 5 와 같다.

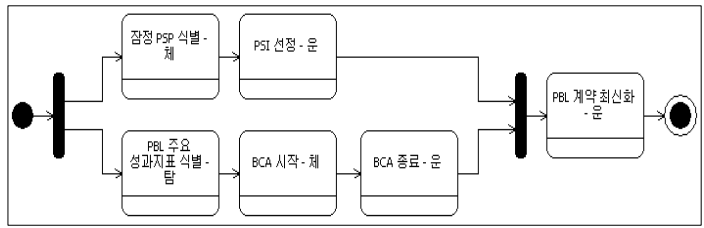

[그림 5] 수명주기별 PBL 프로세스(AFLMA)

[Fig. 5] PBL Process by Life-Cycle(AFLMA)

\subsection{DoD 기준서상의 PBL 모델링}

$\mathrm{DoD}$ 기준서에서는 PBL 수행업무를 AFLMA 기준서 보다 더 구체적으로 정의하고 있다[11]. 수행업무 뿐만 아니라 개발단계별 관련된 문서 - $\mathrm{ICD}$ (초기성능문서), 
$\mathrm{CDD}$ (성능개발문서), $\mathrm{CPD}$ (성능생산문서) - 와의 $\mathrm{PBL}$ 관 련 내용을 식별하고 있다. 또한, PSI의 성능 요구사항 식 별, 군수성과지표 최신화, $\mathrm{PBL}$ 지원 개념 개발이 추가되 었다. 따라서 이러한 내용을 바탕으로 PBL 업무간의 선 후관계를 고려하여 모델링한 결과는 그림 6 과 같다.

\subsection{PBL 프로세스 개선안}

본 연구에서는 $\mathrm{DoD}$ 모델을 기반으로 PBL 팀 구성과 $\mathrm{PBA}$ 준비 업무를 추가로 반영하였으며, 운용단계에서의 계속적인 평가업무를 수정 반영하였다. 반영 내용으로 PBL 업무절차 상의 PBL 팀 구성 업무를 선정하여 체계 개발 초기업무로 분류하였으며, $\mathrm{PBA}$ 준비 업무를 선정 하여 PBL $\mathrm{BCA}$ 수행 전 업무로 추가하였다. 아울러, 필 요시 PBL 계약 수정 업무를 실행 및 평가 업무로 대체하 여 반영하였다. 이를 통하여 NAVSEA와 DAU에서 제시 한 PBL 업무절차를 $\mathrm{DoD}$ 상의 $\mathrm{PBL}$ 업무에 통합 반영함으 로써 개선된 PBL 업무프로세스를 그림 7과 같이 정립할 수 있었다.

\section{5. $\mathrm{PBL}$ 프로세스 개선안과 ILS 분석절차와의 상호 연계방안}

ILS 수행절차는 각 개발주체에 따라 약간의 상이성이 있을 수 있지만 본 연구에서는 ILS 기본 수행업무절차로 MIL-STD-1388-1A 표준서와 DoD 지침서를 기준으로 기
존 ILS 개발 모델과 상기에서 제시된 PBL 프로세스 개선 안 모델간의 상호 연계성을 구현하였다. 이는 PBL 개념 을 기존 ILS 개발 절차와 별도로 분류해서 수행하는 대 신 개발 체계에 있어서 개발단계부터 반영할 수 있는 상 호 연관관계를 정립하였다. 이를 통하여 $\mathrm{PBL}$ 의 장점을 ILS 개발업무에 반영함으로써 ILS 개발업무 시 운용단계 의 $\mathrm{PBL}$ 운용개념을 고려할 수 있게 되었다. 또한, $\mathrm{PBL}$ 은 총수명주기체계관리(TLCSM; Total Life Cycle Systems Management) 측면의 비용 최소화를 목적으로 한다. 따라 서, 기존의 양산 이후 단계에서 PBL 계약 및 적용하는 현 실에서 개발단계부터 적극적으로 ILS 요소 개발에 PBL 개념을 적용함으로써 $\mathrm{PBL}$ 목적달성을 위한 설계 반영활 동이 가능하다.

\subsection{MIL-STD-1388-1A 표준서상의 ILS 분석 절차와의 연계성}

$\mathrm{PBL}$ 의 성과지표는 가용도, 신뢰도, 준비태세, 군수지 원비용 등을 고려하고 있다. 이러한 성과지표를 고려하기 위해서 우선 ILS 개발단계에서 사용자의 운용연구가 선 행되어야 한다. 운용연구를 통하여 PBL 적용 여부 등의 향후 운용상에서의 정책을 개략적으로 설정할 수 있다. 탐색개발단계에서는 시스템 수준(완제품, 서브시스템 등) 에 따른 정비, 보급 관련하여 수행주체를 군직과 민수로 정하는 지원체계대안을 선정하고 관련 대안분석을 수행 하여야 한다. 이는 기존 ILS 업무의 시스템 수준별 정비, 보급정책 결정에 각 시스템별 업무 수행주체를 포함한

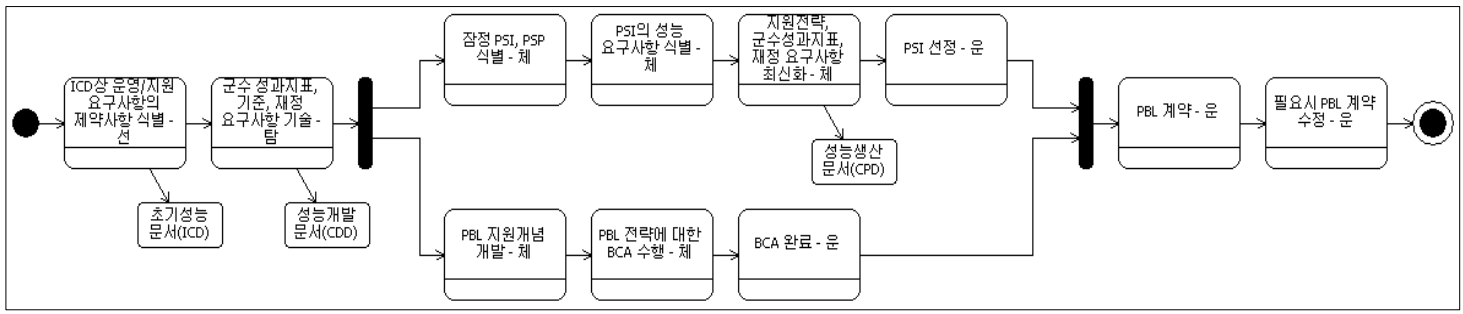

[그림 6] 수명주기별 PBL 프로세스(DoD)

[Fig. 6] PBL Process by Life-Cycle(DoD)

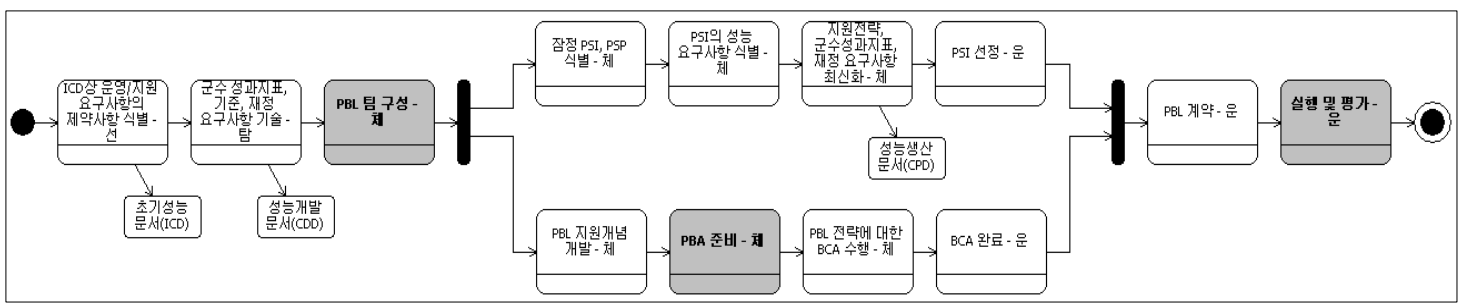

[그림 7] PBL 프로세스 개선안

[Fig. 7] Improved PBL Process 
개념으로 발전될 수 있다. 체계개발단계에서는 선정된 정 책에 군수지원분석 개념이 확정되며 이에 대한 세부 수 행 절차와 관련된 업무분석을 수행한다. 생산/운용단계에 서는 양산 후 지원 업무를 수행하며 지원성 시험/평가는 PBL 평가와 통합하여 수행함으로써 ILS 개발내용이 $\mathrm{PBL}$ 개념과의 연계성으로 확인할 수 있다.

이를 종합하여 MIL-STD-1388-1A 표준서상의 ILS 분
석절차와 제안된 PBL 프로세스 개선안과의 연계성을 표 현하면 그림 8과 같다.

\subsection{DoD 지침서상의 ILS 분석절차와의 연계성}

$\mathrm{ICD}$ 상의 운영 및 지원 요구사항에 대한 제약사항은 ILS 개발의 지원 및 정비개념, 기술에 대한 생성/평가/선 택과 관련되며 군수성과지표, 기준, 재정 요구사항 기술
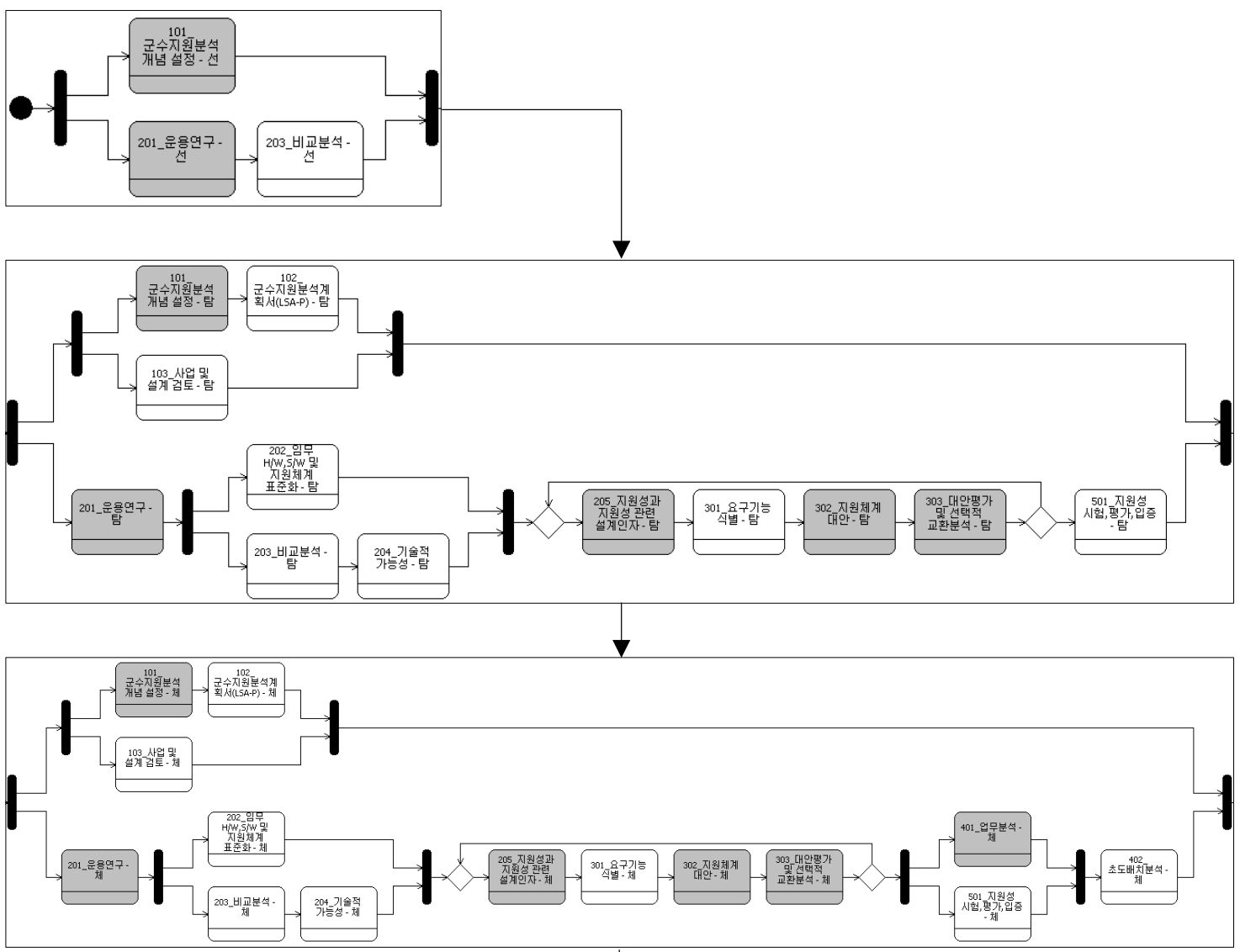

[그림 8] ILS 개발프로세스(MIL-STD-1388-1A)의 PBL 연계성 식별

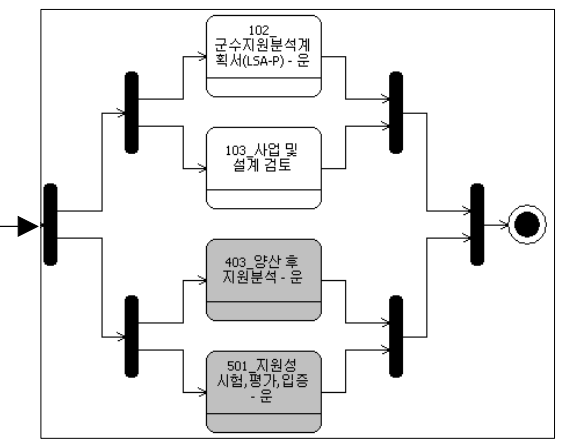

[Fig. 8] Identification of ILS Development Process(MIL-STD-1388-1A) Related to PBL 


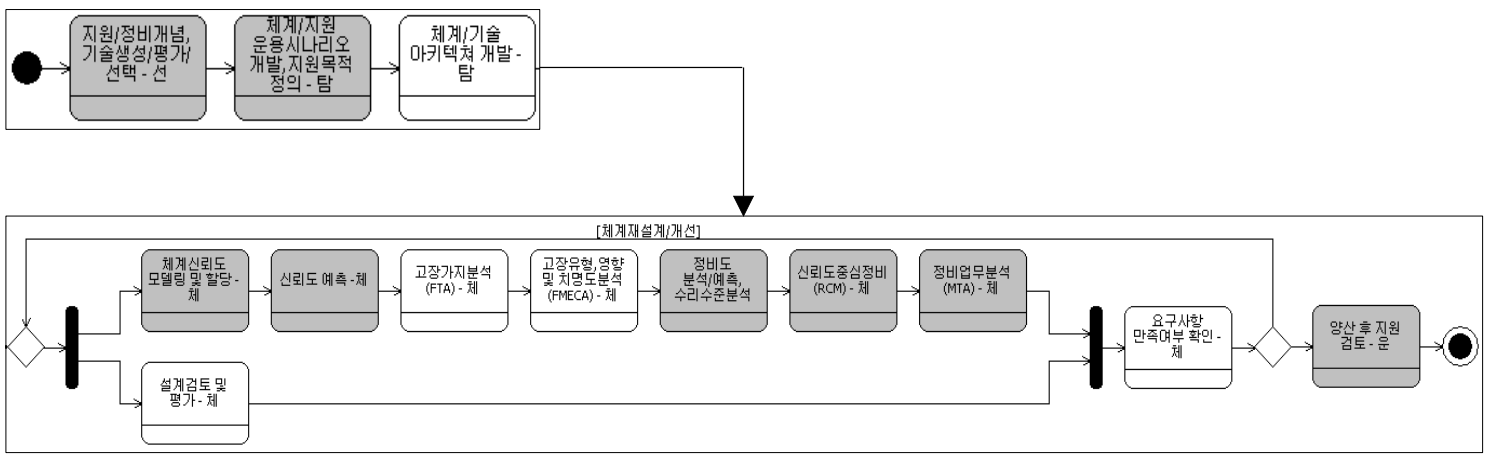

[그림 9] ILS 개발프로세스(DoD)의 PBL 연계성 식별

[Fig. 9] Identification of ILS Development Process(DoD) Related to PBL

은 ILS 개발의 체계/지원 운용시나리오 개발 및 체계지원 목표 설정과 밀접한 관련이 있다. PBL 성과지표의 하나 인 신뢰도에 대하여 체계개발 단계의 체계신뢰도에 대한 모델링, 할당 및 예측을 통하여 운용단계의 요구도를 설 계단계에서 반영할 수 있다. PBL 지원개념은 체계개발 단계에서 시스템 수준별 수리수준분석과 각 수행주체 결 정을 포함하며 신뢰도 중심정비를 통한 예방정비 업무 등의 정비업무분석에 대한 수행주체, 방법, 지원장비 등 의 지원요소를 고려하여야 한다. 이를 통하여 개발된 ILS 요소에 대한 요구사항 충족여부를 판단하여 필요시 체계 재설계 등의 개선활동을 수행하여 양산을 진행한다. 생산 /운용단계에서 $\mathrm{PBL}$ 의 실행 및 평가활동을 통하여 $\mathrm{PBL}$ 성과지표 만족여부를 확인하고 이는 ILS 개발절차상의 양산 후 지원검토업무와 연계성을 갖고 수행할 수 있다.

$\mathrm{DoD}$ 지침서상의 $\mathrm{ILS}$ 분석절차와 제안된 $\mathrm{PBL}$ 프로세 스 개선안과의 연계성을 표현하면 그림 9 와 같다.

\section{6. 결론}

국외에서 PBL 적용 프로세스는 기관별로 적용 절차가 상이하다. 따라서 국내 체계개발 환경에 맞추기 위해 관 련 자료간의 업무 내용을 분석한 후 상호 상이성을 분석 하여 개선된 수명주기별 PBL 프로세스를 도출하였다.

프로세스 모델링을 통하여 제시된 PBL 프로세스 개선 안과 기존 ILS 분석절차와 상호 연계성을 설정하였다. 이 를 통하여 기존의 PBL개념과 ILS의 보급체계와의 연계 성에만 국한된 개념에서 개발체계의 가용도, 신뢰도, 군 수지원비용 등을 반영할 수 있는 개선안을 제시하였다. 결과를 활용하여 $\mathrm{PBL}$ 의 장점을 ILS 요소개발 업무에 적 용함으로써 연구개발의 개발단계부터 PBL을 고려한 ILS 분석업무에 활용될 수 있게 된다. 향 후 본 연구의 개선
안을 비용분석 모델과의 연계를 통하여 성과지표 및 지 원체계 대안에 대한 비용 대 효과분석을 추가로 수행할 필요가 있다. 이 때 적용대상 체계의 비용관련 기초자료 수집 및 수리수준 분석이 고려되어야 한다.

\section{References}

[1] D. Nowiki et al., "A Framework for Performance Based Logistics: A System of Systems Approach," 2010 Intl. Congress on Ultra Modern Telecomm. \& Control Systems and Workshops (ICUMT), pp. 681692, 2010.

[2] Defense Acquisition University, "Performance Based Logistics: A Program Manager's Product Support Guide," Mar. 2005.

[3] Huh, M. S., "KT-1 Performance Based Logistics (PBL) Implementation Plan," KT-1 Operational Efficiency Workshop, Sep. 2010.

[4] K. S. Lee, "A Study on the Application of Performance Based Logistics Contracts," Security Management Institute, 2009.

[5] MIL-STD-1388-1A, "Logistic Support Analysis", Apr. 1983.

[6] The Office of Secretary of Defense, "Designing and Assessing Supportability in DOD Weapon Systems: A Guide to Increased Reliability and Reduced Logistics Footprint," Oct. 2003.

[7] Naval Sea Systems Command, "A Program Manager's Guide to the Application of Performance Based Logistics," Sep. 2005.

[8] L. Garvey, "NAVICP's PBL Perspective," Naval Inventory Control Point, Nov. 2004.

[9] D. S. Kim, "A Study on the Development of Aircraft 
Logistics Support System : Focused on the Performance Based Logistics," Vol.127, pp. 74-152, Air University, Feb. 2011.

[10] K. Pettingill, et al., "Performance Based Logistics (PBL) Partnerships: Assessment of Implementation Methodologies for Selected ACAT 1\&2 Systems," Air Force Logistics Management Agency, Oct. 2004.

[11] The Office of Secretary of Defense, "DoD Template for Application of TLCSM and PBL In the Weapon System Life Cycle," Mar. 2003.

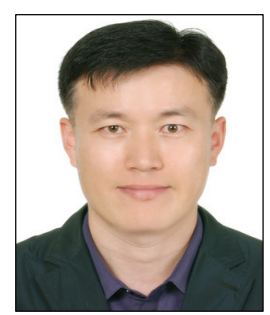

- 1993년 2월 : 전남대학교 공과대 학 산업공학과 (공학석사)

- 1993년 3월 현재 : 국방과학 연구소 선임연구원

- 2011년 8월 현재 : 아주대학 교 시스템공학과 박사과정

<관심분야>

종합군수지원(ILS), 성과기반군수지원(PBL)

이 재 천(Jae-Chon Lee)

[정회원]

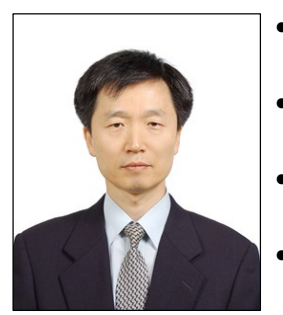

- 1977년 2월 : 서울대학교 공과대 학 전자공학과 (공학사)

- 1979년 2월/1983년 8월 : KAIST 통신시스템 (석/박사)

- 1984년 9월 1985년 9월 : 미 국 MIT Post Doc 연구원

- 1985년 10월 1986년 10월 : 미국 Univ. of California 방문연 구원

- 1990년 2월 1991년 2월 : 캐나다 Univ. of Victoria (Victoria, BC) 방문교수

- 2002년 3월 2003년 2월 : 미국 Stanford Univ. 방문 교수

- 1994년 9월 현재 : 아주대학교 시스템공학과 정교수

<관심분야>

시스템공학, Modeling \& Simulation, Systems Safety 